(c) American Dairy Science Association, 2006.

\title{
An Evaluation of the Seasonality of Veterinary Treatments for Lameness in UK Dairy Cattle
}

\author{
R. A. Laven ${ }^{1}$ and K. R. Lawrence \\ Institute of Veterinary, Animal and Biomedical Sciences, Massey University, New Zealand
}

\begin{abstract}
Of the 4 main diseases causing lameness in UK dairy cattle, 2 (digital dermatitis and foul-in-the-foot, or interdigital necrobacillosis) are infectious diseases that are commonly associated with similar underfoot conditions, and 2 (sole ulcer and white-line disease) result from subclinical laminitis. Comparison of the seasonality of these 2 diseases can identify whether their own unique risk factors are more important than the risk factors they share. Using a database from 46 veterinarians distributed across the United Kingdom, the seasonality of treatments for these 4 diseases was evaluated. This analysis showed that the seasonality of lameness in UK dairy cattle was significantly reduced in comparison with previous reports from the 1980s. This was primarily due to 1 ) a reduction in the seasonality of digital dermatitis (outbreaks of which accounted for $6.7 \%$ of veterinary reports), with only $60 \%$ of reports during the winter as opposed to $72 \%$ in earlier studies, and 2) a change in the seasonality of white-line disease from a disease that was most commonly seen in the winter (55\% of reports) to a disease that was most commonly reported in the late summer or early autumn, with significantly more reports in August and October than in February. Comparison of the seasonality of digital dermatitis and foul-in-the-foot showed a significant difference in the seasonality of the 2 diseases, with foulin-the-foot being significantly more common compared with digital dermatitis in June and August. This implies that significant risk factors exist for digital dermatitis that are not as important for foul-in-the-foot. The difference in the seasonality of sole ulcer and whiteline disease was even more marked, with white-line disease being significantly more common than sole ulcer from August to October, despite these diseases being more closely linked in the literature than digital dermatitis and foul-in-the-foot. This comparison shows that the seasonality of lameness has changed in the United
\end{abstract}

Received January 29, 2006.

Accepted May 4, 2006.

${ }^{1}$ Corresponding author: r.laven@massey.ac.nz
Kingdom and that white-line disease has significantly different risk factors than sole ulcer.

Key words: seasonality, lameness, veterinary treatment

\section{INTRODUCTION}

On an economic basis, lameness is one of the most important diseases of dairy cattle (Kossaibati and Esslemont, 1997; Grohn et al., 2003); on welfare grounds, it is perhaps the most important disease of the modern dairy cow (Webster, 2001; Whay et al., 2003). We need to better understand the relative importance of the main factors that influence the prevalence of lameness so that better preventative regimens can be developed. In particular, we need to identify whether different causes of lameness have different risk factors. Such a process has proved effective in New Zealand, where identifying the differing risk factors associated with white-line disease (poor herding management) as opposed to sole bruising (farm physical conditions; Chesterton, 2004) has meant that farm-specific prevention regimens can be initiated once the primary disease causing the lameness on that farm has been identified.

In the United Kingdom, the 4 most common causes of lameness in dairy cattle are white-line disease, sole ulcer, digital dermatitis, and foul-in-the-foot, accounting for approximately $50 \%$ of all cases (Hedges et al., 2001). These 4 diseases can be divided into 2 pairs on the basis of conventional wisdom. First, digital dermatitis and foul-in-the-foot are both infectious in etiology (Cruz et al., 2005), and both have been associated with wet underfoot conditions (Weaver et al., 2005). Second, white-line disease and sole ulcer are commonly linked together as claw horn diseases; it is stated that their underlying etiologies are very similar, with both resulting from subclinical laminitis (Weaver et al., 2005). Evaluation of the seasonal nature of these diseases would thus be useful in assessing the importance of the unique risk factors for each disease.

The objective of this report was to use the National Animal Disease Information Service (NADIS) database, which is derived from reports by veterinary practitioners, to evaluate the seasonality of veterinary 
treatments for the 4 main causes of lameness in UK dairy cattle.

\section{MATERIALS AND METHODS}

\section{The NADIS Database}

The NADIS is a network of 40 private veterinary practitioners and the veterinary practices of the $6 \mathrm{UK}$ veterinary schools. Since 1997 the number of veterinarians recording data for NADIS has remained stable and the number of cattle covered has been relatively consistent. For all of their veterinary visits, NADIS veterinarians have recorded a field diagnosis for each condition they observed and the number of cattle affected. Diagnoses were recorded as either individual cases or outbreaks. For individual diseases, such as white-line disease, sole ulcer, and foul-in-the-foot (interdigital necrobacillosis), every case on each farm was added to the database for that disease. For outbreak diseases, such as digital dermatitis, every outbreak on each farm was added to the database for that disease, rather than the number of animals affected. Reexaminations of cases and outbreaks are not included in the database.

\section{Statistical Analysis}

Time series were created for each of the 4 diseases based on the number of NADIS reports, for the proportion of sole ulcer reports to white-line disease reports, and for the proportion of digital dermatitis reports to foul-in-the-foot reports. Each time series was partitioned into seasonal, trend, and irregular components using the STL filtering procedure, a seasonal-trend decomposition procedure based on local regression ("loess") smoothing (Cleveland et al., 1990). Loess is a statistical model that fits a local regression model with 1 or more continuous explanatory variables using nonparametric techniques to produce a smoothed model surface. The STL procedure has a simple design that consists of a sequence of applications of loess smoothing, allowing analysis of large amounts of trend and seasonal smoothing. In the seasonal window, periodic smoothing was used, with the span used for the smoothing being the mean of each month's values; in the trend window, the default for the STL package was used. A robust smoothing procedure was used to reduce the impact of outliers. The fitted values from the trend lines were then subtracted from the original data to give the de-trended data. The autocorrelation function (ACF) was then calculated for the de-trended data and plotted for up to 36 lags to confirm that a time series model was more appropriate for these data than a simple constant plus error model.
The significance of any potential periodicity in the de-trended data was tested by fitting a linear regression model with the de-trended data as the dependent variable, and with month, as a factor with the pattern of its levels specified, as the independent variable. The reference month used was February. For this analysis, to account for the effect of month length on the number of NADIS reports, the data analyzed were the mean number of reports per month divided by the number of days in the month. When comparison between groups of months was undertaken, Welch's 2-sample $t$-test was used to compare the amalgamated groups. All statistical analyses were undertaken using $R$ version 2.2.0 (Ihaka and Gentleman, 1996).

\section{RESULTS}

A total of 349,059 cattle reports were made by NADIS veterinarians during the 8-yr period from January 1997 to December 2004, of which 48,720 were for lameness and 21,652 were for white-line disease, sole ulcer, foulin-the-foot, or digital dermatitis. The data for each of the four diseases are summarized in Table 1. Figure 1 summarizes the monthly and yearly trends in the total number of reports submitted by NADIS veterinarians for each of the 4 diseases.

\section{Overall}

Overall, there was no effect of month on the number of reports of lameness by NADIS veterinarians $(P>0.1$; Figure 2). When the data from May to October were combined and compared with the data from November to April (Murray et al., 1996), there were no differences in the number of reports $(P>0.6)$, with $49 \%$ of cases being reported between May and October and $51 \%$ between November and April $(P>0.7)$. When only the data regarding white-line disease, sole ulcer, digital dermatitis, and foul-in-the-foot were included, there was a seasonal effect, with only July having significantly fewer reports than February $(P=0.016)$. As with total lameness reports, amalgamation of the data by season did not result in any seasonal differences $(P$ $>0.6)$.

\section{Digital Dermatitis and Foul-in-the-Foot}

For digital dermatitis there was an effect of month on the number of reports of disease, with June to October all having fewer reports than February $(P<0.01)$. However, the overall effect of season for foul-in-the-foot was not significant, with only January being significantly different from February $(P=0.02$, Figure 3$)$. 
Table 1. Treatment rates (95\% confidence limits) for lameness during the period 1997 to 2004, with subdivision into treatment rates for the 4 most commonly reported diseases and for those 4 diseases individually

\begin{tabular}{|c|c|c|c|c|}
\hline Item & Reports & $\begin{array}{l}\text { Percentage of all } \\
\text { NADIS }^{1} \text { reports }\end{array}$ & $\begin{array}{l}\text { Percentage of total } \\
\text { lameness reports }\end{array}$ & $\begin{array}{l}\text { Percentage of } \\
4 \text { main diseases }\end{array}$ \\
\hline Total lameness reports & 48,720 & $14.2(13.7$ to 14.7$)$ & - & - \\
\hline Total reports for the 4 most common diseases & 21,652 & $6.2(6.1$ to 6.3$)$ & $44.2(42.8$ to 45.7$)$ & - \\
\hline Sole ulcer & 7,710 & 2.2 & $15.9(16.7$ to 15.2$)$ & $35.6(35.0$ to 36.2$)$ \\
\hline Digital dermatitis & 3,299 & 0.9 & $6.7(6.2$ to 7.1$)$ & $15.2(14.5$ to 15.7$)$ \\
\hline Foul-in-the-foot & 3,057 & 0.9 & $6.2(5.8$ to 6.6$)$ & $14.1(13.7$ to 14.6$)$ \\
\hline
\end{tabular}

${ }^{1}$ National Animal Disease Information Service.

\section{White-Line Disease and Sole Ulcer}

For white-line disease, there were more reports in August and October than in February $(P=0.04$ and 0.008 , respectively). In contrast, for sole ulcer there were fewer reports in July and September than in February $(P=0.01$, Figure 4$)$.

\section{Comparison of Digital Dermatitis Reports with Foul-in-the-Foot Reports}

Figure 5 summarizes the changes with time and season in the number of digital dermatitis reports divided by the number of foul-in-the-foot reports. The seasonality of this ratio, as shown by the ACF, was moderate,
A

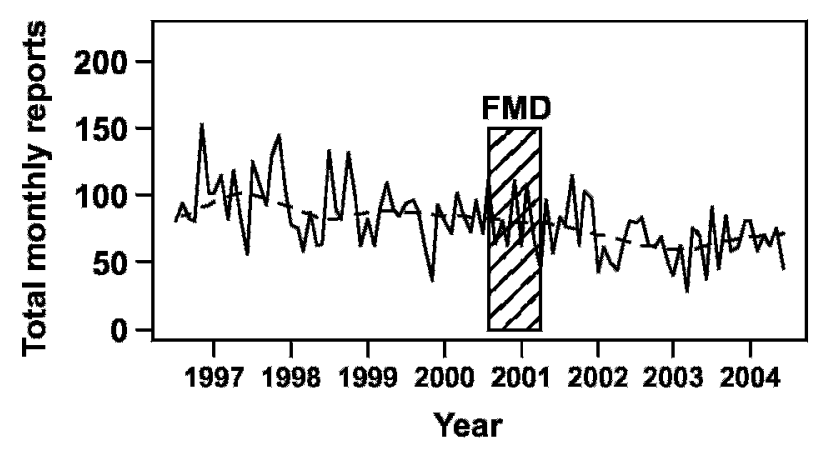

C

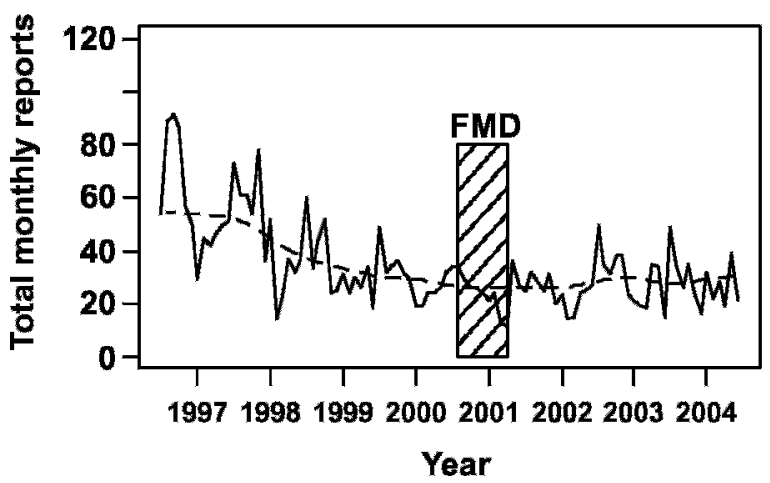

B

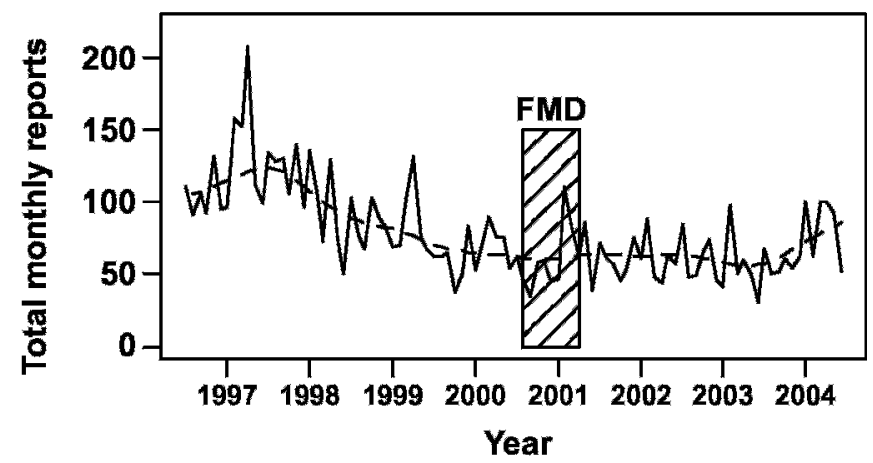

D

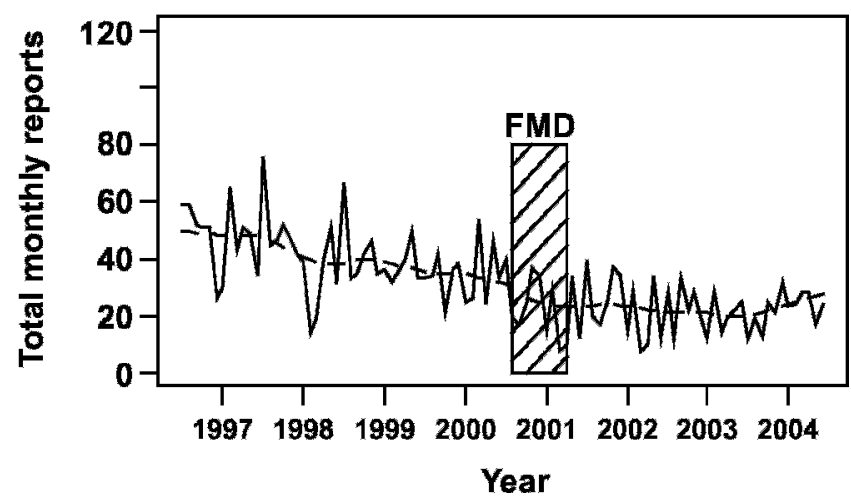

Figure 1. Time series of reports by National Animal Disease Information Service (NADIS) veterinarians for each of the 4 diseases from January 1997 to December 2004. The broken lines are smoothed "loess" trend lines. The shaded area indicates the time of the 2001 outbreak of foot-and-mouth disease (FMD), which significantly affected NADIS veterinary activity. (A) Sole ulcer; (B) white line disease; (C) digital dermatitis; (D) foul-in-the-foot. 


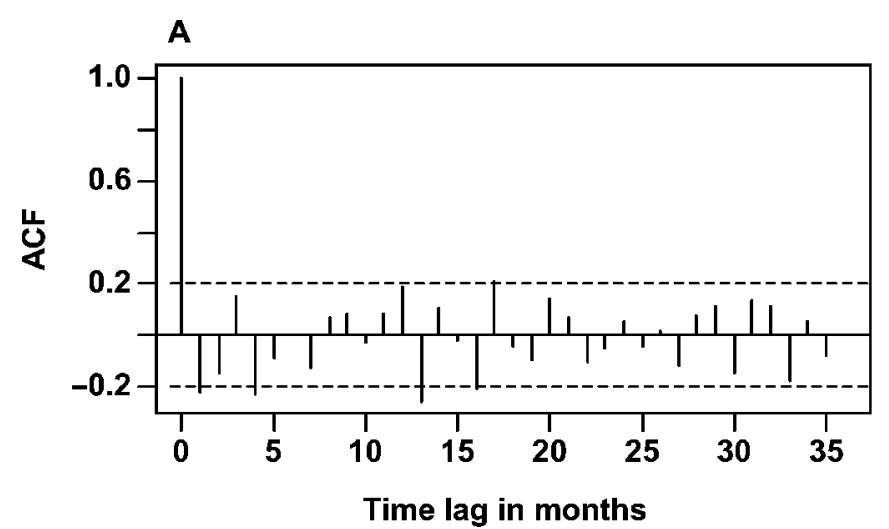

B

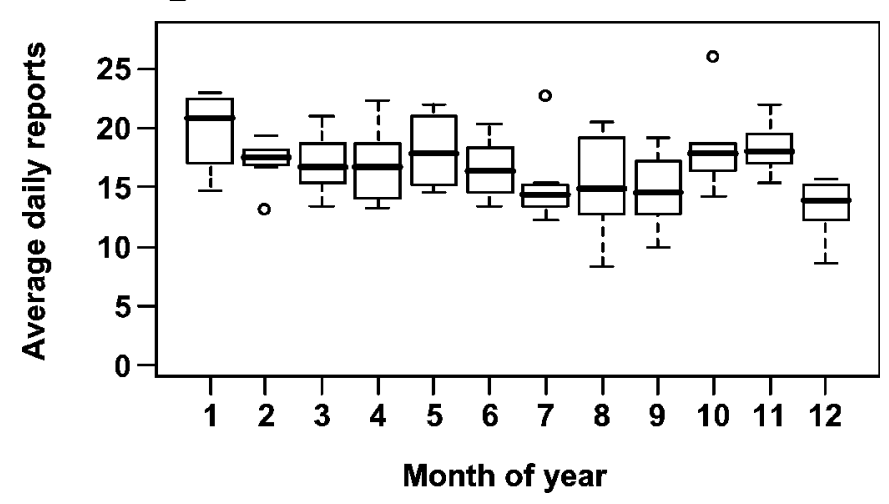

Figure 2. Seasonality of the total number of reports for all 4 diseases. (A) The autocorrelation function (ACF) with $95 \%$ confidence limits for the de-trended monthly time series of lameness reports from January 1997 to December 2004. [This function is the correlation between 2 time points (referred to as lags) for the same random variable (i.e., the number of monthly reports). An ACF significantly different from 0 (either positive or negative) indicates that the relationship is nonrandom; the greater the difference, the greater the correlation, so the pattern of the ACF identifies seasonality.] (B) Box plots showing the total number of reports of lameness by National Animal Disease Information Service veterinarians by month of reporting for de-trended data. Interpretation of box plots: The central box spans the quartiles; the line in the box marks the median. Observations at more than $1.5 \times$ the interquartile range are plotted individually as possible outliers (open circles). Lines extend from the box to the smallest and largest observations that are not suspected outliers.

but the ratio was markedly lower in June and August than in February $(P<0.05)$.

\section{Comparison of Sole Ulcer Reports with White-Line Disease Reports}

Figure 6 summarizes the changes with time and season in the number of white-line reports divided by the number of sole ulcer reports. There was a marked seasonality to this ratio, as is clearly shown by the ACF, with the ratio being higher in August, September, and October than in February $(P<0.01)$.
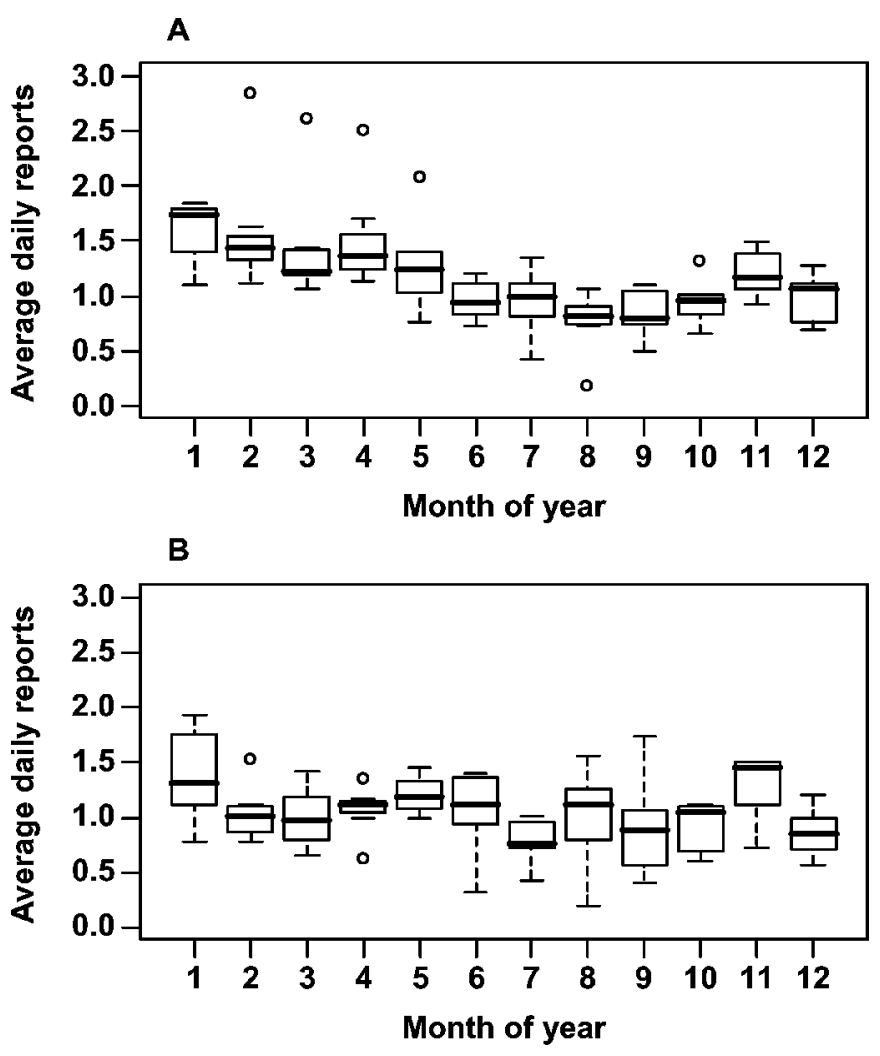

Figure 3. Relationship between month of reporting and reporting by National Animal Disease Information Service veterinarians of lameness caused by digital dermatitis or foul-in-the-foot. (A) Box plots showing the total number of reports of digital dermatitis outbreaks by month of reporting for de-trended data. (Open circles indicate outliers at more than $1.5 \times$ the interquartile range.) (B) Box plots showing the total number of reports of foul-in-the-foot by month of reporting for de-trended data.

\section{DISCUSSION}

\section{Seasonality of Total Reports}

Overall, total reports of lameness by NADIS veterinarians were not seasonal, either on a monthly basis or when the winter housing period was compared with the summer grazing period. When reports of the 4 main diseases alone were analyzed, there was a similar lack of seasonality; by month, only July was significantly different from February and the comparison of "housing" and "grazing" resulted in no significant differences. This is significantly different from most previous UK reports. Murray et al. (1996) reported that over $60 \%$ of cases of digital dermatitis, foul-in-the-foot, white-line disease, and sole ulcer occurred during the winter (November to April); in contrast, only $51 \%$ of NADIS reports occurred during this period. Because the data used by Murray et al. (1996) came from records made by farmers, stockpersons, and veterinary practitioners, this difference may be due to an increased likelihood 


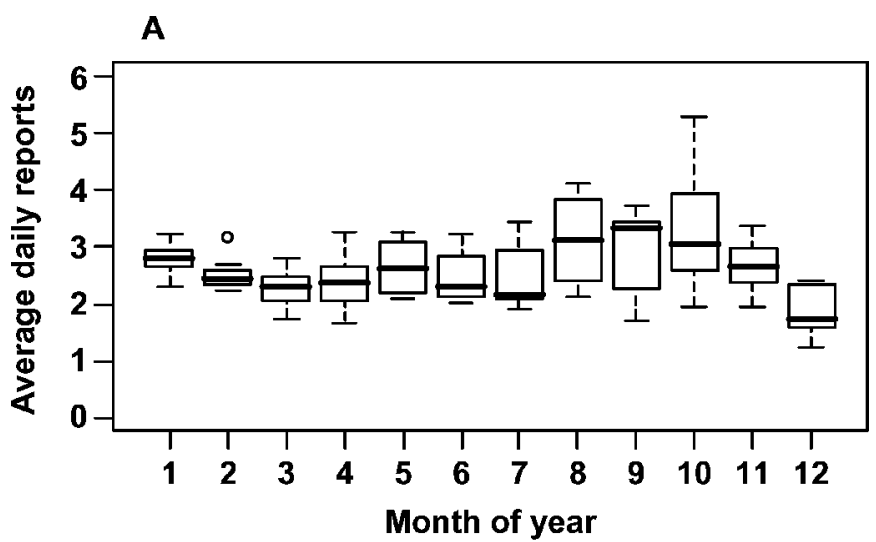

B

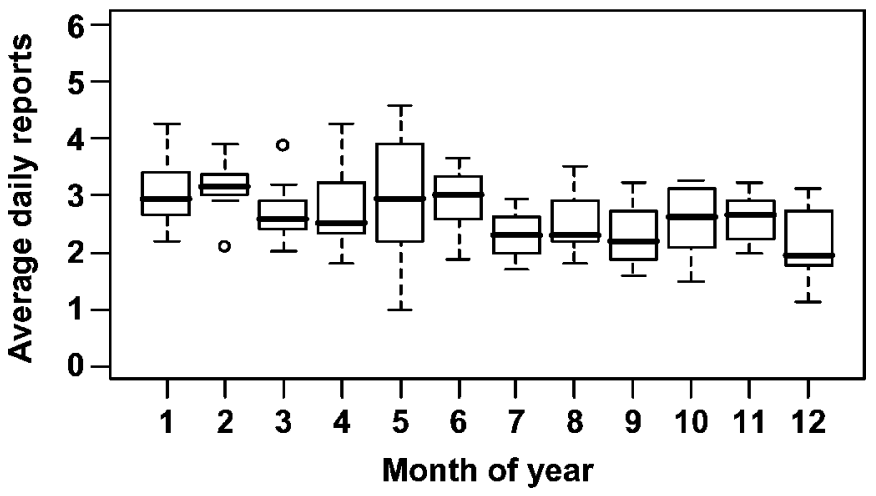

Figure 4. Relationship between month of reporting and reporting by National Animal Disease Information Service veterinarians of lameness caused by white-line disease or sole ulcer. (Open circles indicate outliers at more than $1.5 \times$ the interquartile range.) (A) Box plots showing the total number of reports of white-line disease by month of reporting for de-trended data. (B) Box plots showing the total number of reports of ulcer by month of reporting for de-trended data.

that veterinarians will be called to treat lame cows in the summer rather than in the winter. However, previous veterinary-only reports (Eddy and Scott, 1980) reported a significant seasonality. The NADIS data thus suggest that since the early $1990 \mathrm{~s}$, when the data used by Murray et al. (1996) were collected, overall lameness in the UK dairy herd has become less seasonal, as has the combined lameness rate caused by sole ulcer, white-line disease, foul-in-the foot, and digital dermatitis. This is consistent with the findings from farmers' records of 300 UK dairy herds collected between 1998 and 2002 (Whitaker et al., 2004), which found no effect of month or season on the number of lame cows.

\section{Seasonality of the Individual Diseases}

Digital Dermatitis and Foul-in-the-Foot. Digital dermatitis reports by NADIS veterinarians had marked seasonality and a significant association with housing.
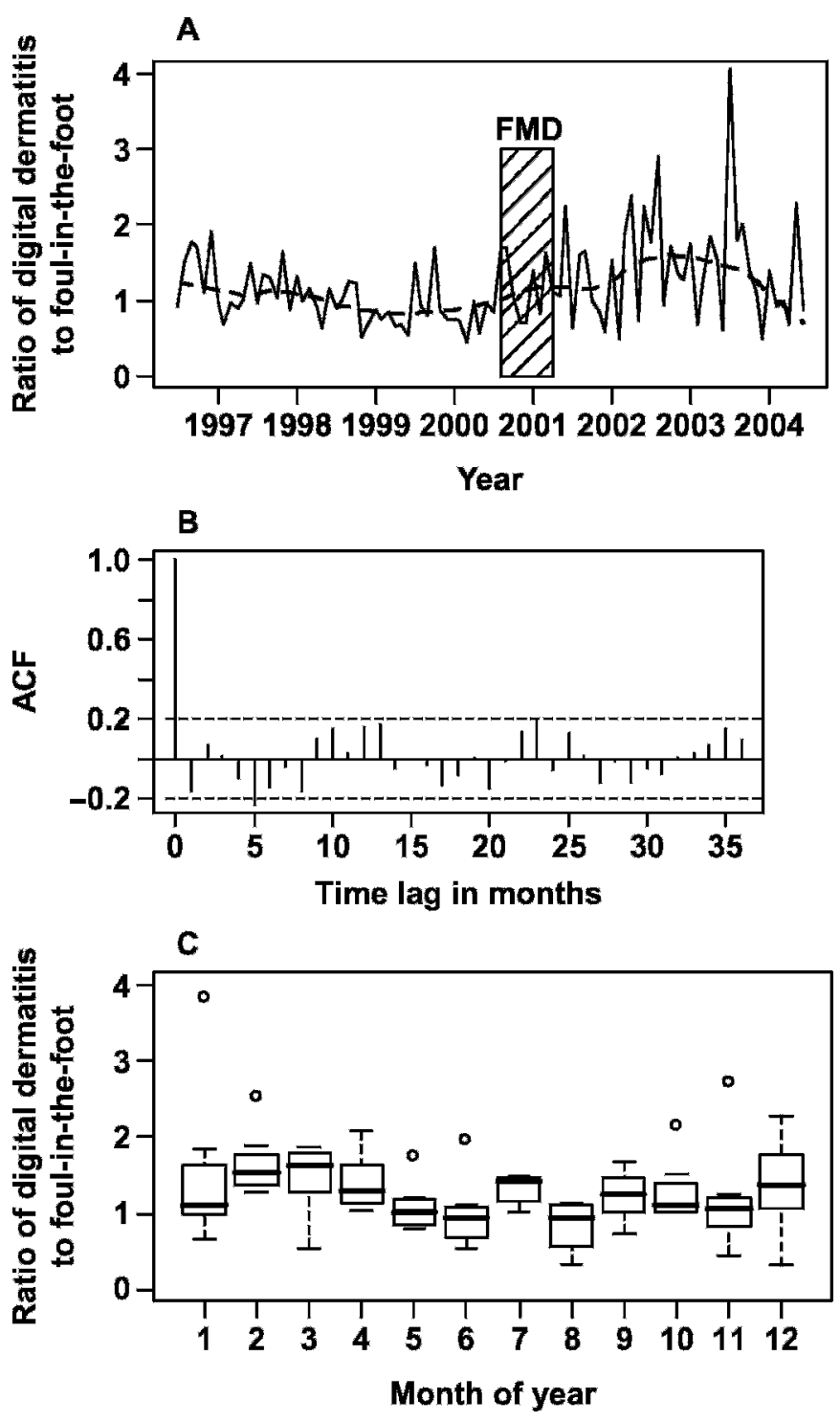

Figure 5. Comparison of the seasonality of treatments for digital dermatitis with those for foul-in-the-foot. (The shaded area labeled FMD marks the time of the 2001 UK outbreak of foot-and-mouth disease.) (A) The time series of the ratio of digital dermatitis to foulin-the-foot reports per month from January 1997 to December 2004. The broken line is a smoothed "loess" trend line. (B) The autocorrelation function $(\mathrm{ACF})$, with 95\% confidence limits, for de-trended monthly time series of the ratio of digital dermatitis to foul-in-thefoot from January 1997 to December 2004. (C) Box plots showing the ratio of digital dermatitis to foul-in-the-foot reports by month of reporting (de-trended data; open circles indicate outliers at more than $1.5 \times$ the interquartile range).

This is a consistent finding in reports of the epidemiology of digital dermatitis (Murray et al., 1996; Somers et al., 2005). However, comparison of the NADIS data, in which $60 \%$ of cases were reported during the winter, with that of Murray et al. (1996), who found that $72 \%$ of cases occurred during winter, strongly suggests that 
A

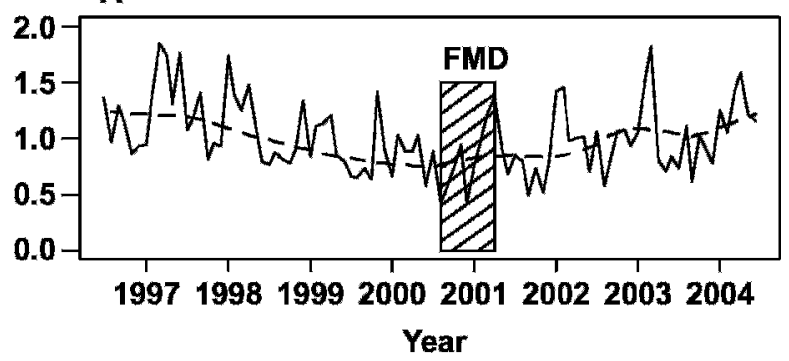

B
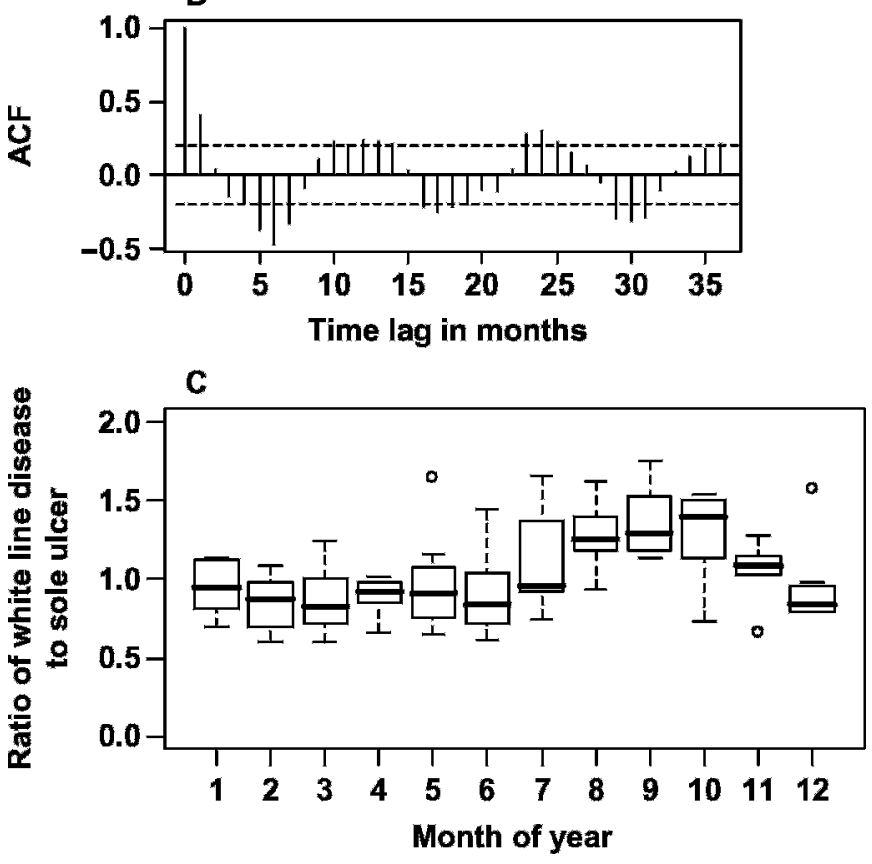

Figure 6. Comparison of the seasonality of treatments for sole ulcer with those for white-line disease. The shaded area labeled FMD marks the time of the 2001 UK outbreak of foot-and-mouth disease. (A) Time series of the ratio of white-line disease to sole ulcer reports per month from January 1997 to December 2004. The broken line is a smoothed "loess" trend line. (B) The autocorrelation function (ACF), with $95 \%$ confidence limits, for the de-trended monthly time series of the ratio of white-line disease to sole ulcer reports from January 1997 to December 2004. (C) Box plots showing the ratio of white-line disease to sole ulcer reports by month of reporting for de-trended data. (Open circles indicate outliers at more than $1.5 \times$ the interquartile range.)

the seasonality of digital dermatitis has been reduced since 1991, consistent with data from The Netherlands (Somers et al., 2003). This change in seasonality is probably associated with the continued spread of digital dermatitis between farms and within farms since 1991 . Most UK farms now have endemic digital dermatitis, which persists into the grazing period. This means that to effectively control digital dermatitis, measures aimed at managing the condition, such as routine foot bathing, must be maintained during the grazing period, and attention must be paid to reducing contact with mud, particularly around feeding areas and entrances to fields.

For foul-in-the-foot, the NADIS data had only limited seasonality, peaking in January with lower but consistent numbers during the rest of the year. Previous reports of seasonality have been inconsistent, but have found peaks in autumn and early winter (Eddy and Scott, 1980; Rowlands et al., 1985). Alban et al. (1995) reported that in Danish cattle the peak in foul-in-thefoot cases occurred between June and September, earlier than in the United Kingdom. They suggested that this was due to the colder Danish climate reducing the growth of Fusobacterium necrophorum in winter. However, the NADIS peak in January suggests that external temperature is of limited importance in determining the prevalence of foul-in-the-foot. Further research is required into the factors that influence the incidence of foul-in-the-foot in UK cattle and elsewhere.

Previous comparisons of foul-in-the-foot and digital dermatitis have suggested that they have similar seasonality (Murray et al., 1996); however, the NADIS data showed differences in seasonality, with relatively more cases of foul-in-the-foot than digital dermatitis seen in the summer. This implies that there are significant risk factors for foul-in-the-foot that do not influence the prevalence of digital dermatitis, and that the term "bovine digital epidermitis," as used by Cruz et al. (2005), has limited epidemiological applicability.

White-Line Disease and Sole Ulcer. For white-line disease, previous reports have shown seasonality, with significantly more cases reported in winter than summer (Rowlands et al., 1985; Murray et al., 1996). The NADIS data show seasonality, but they suggest that white-line disease is a disease of the summer, not winter. This change in seasonality indicates that there may have been a change in the underlying risk factors associated with the development of white-line disease, with an increase in the importance of factors present before the time when dairy cattle in the United Kingdom are traditionally housed (September and October).

For sole ulcer, previous reports have shown seasonality, with increases in reports toward the end of the housing period (Rowlands et al., 1985). The NADIS data were less seasonal. Although, there were significantly fewer treatments for sole ulcer in July and September than in February, the peak associated with late winter in reports by Rowlands et al. (1985) and Eddy and Scott (1980) continued in the NADIS reports until June. It is likely that the extension of this peak period is strongly related to changes in farm management, with cattle being kept indoors longer, and even when outdoors, spending significantly more time on concrete and being given supplementary feed. Continued improvements in 
housing and flooring are essential to reduce the impact of these management changes.

The significant differences in the seasonality of these 2 diseases when analyzed separately is even more marked when the data are compared, with white-line disease being consistently more commonly reported during the summer. Hence, despite these 2 diseases being commonly thought of as having similar underlying etiologies (Ossent and Lischer, 1998), they have markedly different seasonalities. The NADIS data add to recent research suggesting that white-line disease and sole ulcer are distinct entities that have no significant association in individual cows (LeFevre et al., 2001), with different temporal and spatial patterns (Offer et al., 2000; LeFevre et al., 2001) and differing responses to biotin supplementation (Hedges et al., 2001).

Furthermore, whereas the changes in sole ulcer seasonality appear strongly linked to lengthening of the housing period, with more cases in late spring and early summer, the change in white-line disease seasonality cannot be so linked. White-line disease is most common around housing time, so unlike sole ulcer, its peak cannot be associated with a cumulative effect of contact with concrete. It is possible that one trigger for whiteline disease is the change from pasture to housing, but this risk factor has always been present and previous reports have not suggested any such link. It is thus most likely that white-line disease occurs at the end of the grazing period as a cumulative effect of damage accumulated during that period. The NADIS data suggest that the etiology of many cases of white-line disease is similar to that seen in New Zealand, where white-line disease is by far the most common cause of lameness (Chesterton, 2004); that is, the underlying cause of the rise in white-line disease is poor management of cows while herding them for milking and walking them to the parlor. Further research is required to establish whether this suggestion is correct. In particular, we need to know the housing status of cows with whiteline disease and whether there is any link to calving. However, the seasonality of white-line disease shown by the NADIS data suggests that greater attention needs to be paid to the maintenance of tracks and herding management in European dairy cattle.

\section{CONCLUSIONS}

The NADIS data show that lameness in UK dairy cattle is now less seasonal than previously reported. Some of this change is due to changes in the calving pattern of UK cattle, because lameness is less seasonal than it was $15 \mathrm{yr}$ ago (Esslemont, 2003) and the onset of lameness is significantly associated with calving (Green et al., 2002). However, this is unlikely to be the whole explanation because Rowlands et al. (1985) found no effect of calving on the seasonality of lameness even though calving was significantly more seasonal in the early 1980 s, when that study was undertaken, than it is currently. The NADIS data suggest that it is primarily changes in the patterns of digital dermatitis and whiteline disease that have resulted in the reduction in seasonality of lameness. Digital dermatitis has become less seasonal, with less reduction in cases during the summer than seen previously, consistent with a changeover in the disease pattern from epidemic to chronic infection. White-line disease has changed in seasonality, becoming more common in late summer. Further research is required to establish the underlying reasons for this change, but it may be associated with a change on some farms to a more New Zealand style of dairying in which cattle are kept on pasture longer, increasing the influence of track quality and management of herding behavior on lameness.

\section{ACKNOWLEDGMENTS}

The authors would like to acknowledge the support of all the NADIS veterinarians and the staff at NADIS for collecting the data used in this analysis.

\section{REFERENCES}

Alban, L., L. G. Lawson, and J. F. Agger. 1995. Foul in the foot (interdigital necrobacillosis) in Danish dairy cows-Frequency and possible risk factors. Prev. Vet. Med. 24:73-82.

Chesterton, R. N. 2004. Linking farm physical conditions, herd management and cow behaviour to the distribution of foot lesions causing lameness in pasture-fed dairy cattle in New Zealand. Pages 200-202 in Proc. 13th Int. Symp. and 5th Conf. on Lameness in Ruminants, Maribor, Slovenija. Zemljic and Co., Slovenija.

Cleveland, R. B., W. S. Cleveland, J. E. McRae, and I. Terpenning. 1990. STL: A seasonal-trend decomposition procedure based on loess. J. Off. Stat. 6:3-73.

Cruz, C. E. F., C. A. Pescador, Y. Nakajima, and D. Driemeier. 2005. Immunopathological investigations on bovine digital epidermitis. Vet. Rec. 157:834-837.

Eddy, R. G., and C. P. Scott. 1980. Some observations on the incidence of lameness in dairy cattle in Somerset. Vet. Rec. 106:140-144.

Esslemont, R. J. 2003. The costs of poor fertility and what to do about reducing them. Cattle Pract. 11:237-250.

Green, L. E., V. J. Hedges, Y. H. Schukken, R. W. Blowey, and A. J. Packington. 2002. The impact of clinical lameness on the milk yield of dairy cows. J. Dairy Sci. 85:2250-2256.

Grohn, Y. T., P. J. Rajala-Schultz, H. G. Allore, M. A. DeLorenzo, J. A. Hertl, and D. T. Galligan. 2003. Optimizing replacement of dairy cows: Modeling the effects of diseases. Prev. Vet. Med. 61:27-43.

Hedges, V. J., R. W. Blowey, A. J. Packington, C. J. O'Callaghan, and L. E. Green. 2001. A longitudinal field trial of the effect of biotin on lameness in dairy cows. J. Dairy Sci. 84:1969-1975.

Ihaka, R., and R. Gentleman. 1996. R: A language for data analysis and graphics. J. Comp. Graph Stat. 5:299-314.

Kossaibati, M. A., and R. J. Esslemont. 1997. The costs of production diseases in dairy herds in England. Vet. J. 154:41-51.

Le Fevre, A. M., D. N. Logue, J. E. Offer, I. McKendrick, and G. Gettinby. 2001. Correlations of measurements of subclinical claw horn lesions in dairy cattle. Vet. Rec. 148:135-138. 
Murray, R. D., D. Y. Downham, M. J. Clarkson, W. B. Faull, J. W. Hughes, F. J. Manson, J. B. Merritt, W. B. Russell, J. E. Sutherst, and W. R. Ward. 1996. Epidemiology of lameness in dairy cattle: Description and analysis of foot lesions. Vet. Rec. 138:586-591.

Offer, J. E., D. McNulty, and D. N. Logue. 2000. Observations of lameness, hoof conformation and development of lesions in dairy cattle over four lactations. Vet. Rec. 147:105-109.

Ossent, P., and C. J. Lischer. 1998. Bovine laminitis: The lesions and their pathogenesis. In Pract. 20:415-427.

Rowlands, G. J., A. M. Russell, and L. A. Williams. 1985. Effects of stage of lactation, month, age, origin and heart girth on lameness in dairy cattle. Vet. Rec. 117:576-580.

Somers, J. G. C. J., K. Frankena, E. N. Noordhuizen-Stassen, and J. H. M. Metz. 2003. Prevalence of claw disorders in Dutch dairy cows exposed to several floor systems. J. Dairy Sci. 86:2082-2093.
Somers, J. G. C. J., K. Frankena, E. N. Noordhuizen-Stassen, and J. H. M. Metz. 2005. Risk factors for digital dermatitis in dairy cows kept in cubicle houses in The Netherlands. Prev. Vet. Med. 71:11-21.

Weaver, A. D., A. Steiner, and G. St Jean. 2005. Lameness. Pages 179-232 in Bovine Surgery and Lameness. 2nd ed. Blackwell Scientific Publications, Oxford, UK.

Webster, A. J. F. 2001. Farm animal welfare: The five freedoms and the free market. Vet. J. 161:229-237.

Whay, H. R., D. C. Main, L. E. Green, and A. J. Webster. 2003. Assessment of the welfare of dairy cattle using animal-based measurements: Direct observations and investigation of farm records. Vet. Rec. 153:197-202.

Whitaker, D. A., A. I. Macrae, and E. Burrough. 2004. Disposal and disease rates in British dairy herds between April 1998 and March 2002. Vet. Rec. 155:43-47. 